\title{
Acquired platinum resistance enhances tumour angiogenesis through angiotensin II type I receptor in bladder cancer
}

\author{
N Tanaka', A Miyajima*,', T Kosaka', Y Miyazaki', S Shirotake', H Shirakawa', E Kikuchi' and M Oya' \\ 'Department of Urology, Keio University School of Medicine, 35 Shinanomachi, Shinjuku-ku, Tokyo I60-8582, Japan
}

\begin{abstract}
BACKGROUND: We investigated the changes in reactive oxygen species (ROS) and angiogenesis through angiotensin II (Ang II) type I receptor (ATIR) after the development of acquired platinum resistance in bladder cancer.

METHODS: Four invasive human bladder cancer cell lines, T24, 5637, T24PR, and 5637PR, were used in vitro, whereas in vivo, T24 and T24PR cells were used. T24PR and 5637PR cells were newly established at our institution as acquired platinum-resistant sublines by culturing in cisplatin (CDDP)-containing conditioned medium for 6 months.

RESULTS: Ang II induced significantly higher vascular endothelial growth factor (VEGF) production in T24PR and 5637PR cells than in their corresponding parent cells in vitro, whereas Ang II induced a further increase in VEGF production. These platinum-resistant cells also showed significantly higher ATIR expression than their corresponding parent cells. ROS was also significantly upregulated in T24PR and 5637PR cells, whereas increased ATIR expression was significantly downregulated by scavenging free radicals. We also demonstrated the efficacy of ATIR blockade at suppressing the growth of platinum-resistant xenograft model.

CONCLUSION: Our findings indicate a new molecular mechanism for upregulated ATIR signalling through increased ROS when tumours progressed after the CDDP-based regimens, and shed light on the importance of ATIR blockade for platinum-resistant bladder cancers.

British Journal of Cancer (201 I) 105, I331-1337. doi:10.1038/bjc.201 I.399 www.bjcancer.com
\end{abstract}

Published online 4 October 2011

(c) 201 I Cancer Research UK

Keywords: cisplatin; resistance; angiotensin I| type I receptor; reactive oxygen species

Bladder cancer is one of the most aggressive epithelial tumours and is characterised by a high rate of early systemic dissemination. Patients with metastatic bladder cancer are routinely treated with cisplatin (CDDP)-based systemic chemotherapy, such as M-VAC (methotrexate, vinblastine, doxorubicin, CDDP) and/or GC (gemcitabine, CDDP) regimens. Although CDDP-based regimens still constitute the gold standard, tumours treated with CDDP ultimately acquire platinum resistance and no standard of care exists following CDDP-based regimens.

Angiotensin II (Ang II) is a key biological peptide in the reninangiotensin system. There are two major subtypes of Ang II receptor: Ang II type 1 receptor (AT1R) and Ang II type 2 receptor (AT2R). Concern regarding the potential role of Ang II in angiogenesis and promotion of tumour growth has been growing (Rivera et al, 2001; Egami et al, 2003; Juillerat-Jeanneret et al, 2004). We previously showed that AT1R signalling led to a potent induction of vascular endothelial growth factor (VEGF) in urogenital cancers (Miyajima et al, 2002; Kosugi et al, 2006; Kosaka et al, 2007, 2010). Moreover, we reported that increased reactive oxygen species (ROS) generation in cancer cells could upregulate AT1R expression and enhance VEGF production in bladder cancer (Tanaka et al, 2010).

Several studies have evaluated the potential roles of ROS generation in angiogenesis and tumour growth, and reported that

*Correspondence: Dr A Miyajima; E-mail: akiram@sc.itc.keio.ac.jp Received 2 August 2011; revised 7 September 2011; accepted 12 September 201 I; published online 4 October $201 \mathrm{I}$
ROS generation could induce the activation of mitogen-activated protein kinase, nuclear factor- $\kappa \mathrm{B}$, activator protein 1 , and VEGF production, all of which are strongly associated with tumour development (Schreck et al, 1992; Stevenson et al, 1994; Puri et al, 1995), although the role of ROS generation in cancer cells remains controversial, because it also increases pro-apoptotic molecules such as p53 and p38 mitogen-activated protein kinase (Lee, 1998; Lau et al, 2010). To the best of our knowledge, the association between ROS generation and angiogenesis after the development of acquired platinum resistance has not yet been fully elucidated. Moreover, there has been no finding suggesting the regulation of AT1R expression in these tumours.

In the present study, we established acquired platinum-resistant bladder cancer cell lines to evaluate the changes in angiogenesis after the development of acquired platinum resistance. Next, focusing on ROS generation, we investigated the regulation of AT1R expression after the development of acquired platinum resistance, and whether AT1R blockade could suppress the growth of platinum-resistant tumours.

\section{MATERIALS AND METHODS}

\section{Reagents}

CDDP and paclitaxel were kindly supplied by Nippon Kayaku Co. (Tokyo, Japan), and the ARB olmesartan was kindly provided by Daiichi Sankyo (Tokyo, Japan). Ang II and mouse monoclonal antibody for beta-actin were purchased from Sigma (Atlanta, GA, 
USA). Gemcitabine, carboplatin, and edaravone (a free radical scavenger) were obtained from Wako Pure Chemical Industries (Osaka, Japan). Mouse monoclonal antibody for CD34 was purchased from Nichirei (Tokyo, Japan). Rabbit polyclonal antibody for VEGF and AT1R were purchased from Santa Cruz Biotechnology, Inc. (Santa Cruz, CA, USA).

\section{Cell lines and culture}

Two invasive human bladder cancer cell lines, T24 and 5637, were obtained from the American Type Culture Collection (Rockville, MD, USA). All cells were routinely maintained in RPMI-1640 (Invitrogen, Carlsbad, CA, USA) supplemented with $10 \%$ fetal bovine serum (Dainippon Pharmaceutical, Tokyo, Japan), at $37^{\circ} \mathrm{C}$ in a humidified $5 \% \mathrm{CO}_{2}$ atmosphere. To develop platinum resistance, T24 and 5367 cells were grown in RPMI-1640 supplemented with $10 \%$ fetal bovine serum containing $\mathrm{CDDP}$, at $37^{\circ} \mathrm{C}$ in a humidified $5 \% \mathrm{CO}_{2}$ atmosphere. The concentration of CDDP was increased to $3 \mu \mathrm{M}$. These cells were passaged upon reaching confluence over a 6 -month period. These new cell lines were named T24PR and 5637PR (acquired platinum resistance for 6 months).

\section{Murine xenograft bladder cancer model}

Six-week old athymic nude BALB/C mice were obtained from Sankyo Lab Service (Tokyo, Japan). T24 and T24PR cells $\left(2 \times 10^{6}\right.$ cells), suspended in $100 \mu \mathrm{l}$ of matrigel (Becton Dickinson Labware, Lincoln Park, NJ, USA), were implanted subcutaneously into the flank of each mouse, and assigned to each group, which consists of 10 animals. Tumour volume was calculated twice a week using the formula: tumour volume $\left(\mathrm{mm}^{3}\right)=$ length $\times$ width $\times$ height $\times 0.52$.

To evaluate the efficacy of the ARB olmesartan, on day 14 after cancer cell implantation, the mice were administered olmesartan ( $10 \mathrm{mg} \mathrm{kg}^{-1}$ per day) by gavage. To investigate the sensitivity to CDDP, the mice were administered CDDP $\left(2\right.$ or $\left.10 \mathrm{mg} \mathrm{kg}^{-1}\right)$ intraperitoneally on day 21 after cancer cell implantation. Paclitaxel ( 5 or $15 \mathrm{mg} \mathrm{kg}^{-1}$ ) was also administered on day 21 after cancer cell implantation. To evaluate the changes in AT1R expression induced by edaravone, the mice were administered edaravone $\left(5 \mathrm{mg} \mathrm{kg}^{-1}\right)$ intraperitoneally daily, beginning on day 14 after cancer cell implantation. All animals were killed on the 28th day, and the subcutaneous tumours were harvested. These experiments were carried out in accordance with the Japanese government guidelines, and the protocol was approved by the Animal Care Committee of our institution.

\section{Cell growth assay}

All cell lines were seeded at a density of $1 \times 10^{4}$ per well into 96 -well culture plates. Following $24 \mathrm{~h}$ incubation in RPMI 1640 medium with $10 \%$ fetal bovine serum, the cells were incubated for the appropriate time with various concentrations of CDDP, paclitaxel, gemcitabine, carboplatin, Ang II, and olmesartan, to investigate the sensitivity of each cell line. At the end of the incubation period, cell viability was determined using a Premix WST-1 Cell Proliferation Assay System (Takara Bio Inc., Shiga, Japan) and microplate spectrophotometer (Bio-Rad Laboratories Inc., Tokyo, Japan).

\section{Apoptosis assay}

Flow cytometric analysis was performed using TUNEL assay to detect apoptosis. TUNEL assay was performed using ApopTag kits (Sigma Chemical). The cells $\left(1 \times 10^{6}\right)$ were seeded in $100-\mathrm{mm}$ dishes, incubated for $24 \mathrm{~h}$ in RPMI 1640 medium with $10 \%$ fetal bovine serum, and then incubated with various concentrations of CDDP. Following $48 \mathrm{~h}$ incubation in medium containing CDDP, apoptosis was detected by flow cytometry, and subsequent analysis was carried out according to the manufacturer's protocol.

\section{Cell extracts and western blot analysis}

Whole-cell extracts were obtained using RIPA buffer (Cell Signaling Technology Japan, Tokyo) containing protease inhibitors, according to the manufacturer's protocol. The extracted whole protein $(50 \mu \mathrm{g})$ with sample buffer containing 2-mercaptoethanol was separated on $12.5 \%$ SDS-PAGE and transferred to a nitrocellulose membrane (Bio-Rad Laboratories, Hercules, CA, USA), and then incubated with $5 \%$ skim milk overnight. The following protocols including primary and secondary antibody were described previously (Tanaka et al, 2010).

\section{Fluorescent assay}

DCFH-DA, which permeates into cells and interacts with intracellular ROS to generate fluorescent dichlorofluorescein (DCF), was used to measure the intracellular levels of ROS generated. The amount of ROS was estimated from DCF production (Cell Biolabs Inc., San Diego, CA, USA) using fluorescence intensity in the cells at $480 \mathrm{~nm}$ excitation per $530 \mathrm{~nm}$ emission, using a fluorometric plate reader (Tanaka et al, 2010). Glutathione and glutathione S-transferase activity were measured by fluorescent assay using a commercially available detection kit (Anaspec, Fremont, CA, USA).

\section{Immunostaining for CD34, VEGF, AT1R, and apoptosis}

Formalin-fixed paraffin-embedded sections $(4 \mu \mathrm{m})$ were deparaffinised, rehydrated, and washed in PBS. Endogenous peroxidase was quenched and sections were blocked with skim milk. Primary antibodies of CD34, VEGF, and AT1R were then applied at room temperature for $1 \mathrm{~h}$. After washing with PBS, they were incubated with secondary antibodies against mouse and rabbit IgG conjugated to a peroxidase-labelled dextran polymer for $1 \mathrm{~h}$.

Microvessel density (MVD) in areas of the tumour was counted with anti-CD34 antibody according to the method reported by Kosugi et al (2009). The intensity of AT1R and VEGF staining was evaluated according to the method described in our previous report (Tanaka et al, 2010). Apoptosis was measured by transferasemediated nick-end labelling assay using a commercially available apoptosis in situ detection kit (Wako Pure Chemical). The apoptosis index was calculated as the average number of transferase-mediated nick-end labelling-positive cells in $\times 400$ fields.

\section{ELISA assay for VEGF in conditioned medium}

Cells were seeded in $60-\mathrm{mm}^{2}$ dishes and allowed to attach at $37^{\circ} \mathrm{C}$ in a humidified $5 \% \mathrm{CO}_{2}$ atmosphere. After $24 \mathrm{~h}$, the medium was replaced with serum-free medium for $4 \mathrm{~h}$. Next, the cells were incubated with conditioned medium. After $20 \mathrm{~h}$, the supernatant was collected and VEGF was measured using a commercially available ELISA kit (Quantikine, R\&D Systems, Minneapolis, MN, USA).

\section{Statistical analysis}

All data are presented as the mean \pm s.e. Statistical analyses were performed using the Mann-Whitney $U$-test. $P$-values $<0.05$ were accepted as being statistically significant. All statistical analyses were performed using commercially available statistical software.

\section{RESULTS}

\section{Establishment of the acquired platinum-resistant bladder cancer sublines in vitro}

Using 5637 and T24 cells, we generated bladder cancer sublines that acquired resistance to platinum, and the cells that were successfully cultured for 6 months in condition medium of CDDP 
were named 5637PR and T24PR. Following 3 months without CDDP-exposure, further examinations were performed. The doubling times of each PR cell line in vitro were slightly increased, compared with their parent cells $(34.0 \pm 3.7 \mathrm{~h}$ in 5637 cells $v s$ $37.0 \pm 2.5 \mathrm{~h}$ in $5637 \mathrm{PR}$ cells, $18.6 \pm 1.4 \mathrm{~h}$ in T24 cells $v s 21.1 \pm 2.2 \mathrm{~h}$ in T24PR cells).

5637PR and T24PR cells were treated with various concentrations of CDDP for $48 \mathrm{~h}$ (Table 1). CDDP did not strongly affect the viability of 5637PR and T24PR cells, compared with their corresponding parent cells. Using the TUNEL assay, we also investigated the apoptosis induced by CDDP. The apoptotic index induced by CDDP $(20 \mu \mathrm{M})$ at $48 \mathrm{~h}$ was $36.4 \pm 12.8 \%$ in 5637 cells, $2.3 \pm 0.6 \%$ in $5637 \mathrm{PR}$ cells, $41.5 \pm 8.7 \%$ in T24 cells, and $2.3 \pm 1.0 \%$ in T24PR cells. These results were correlated with the CDDPinduced cell viability of each cell line. Although no significant difference was observed in the level of glutathione, both 5637PR (1.2-fold) and T24PR (1.3-fold) cells showed slightly higher levels of glutathione S-transferase activity, compared with that of the corresponding parent cells $(P<0.05)$. We then evaluated the changes in sensitivity to other anticancer agents including paclitaxel, gemcitabine, and carboplatin, using a 48-h continuous exposure (Table 1). Under these experimental conditions, both 5637PR and T24PR cells showed cross-resistance to all anticancer agents, whereas the sensitivity of paclitaxel did not change dramatically, compared with the other agents.

\section{Establishment of the acquired platinum-resistant bladder} cancer subline in vivo

To evaluate the acquired platinum resistance in vivo, T24 and T24PR tumours were administered CDDP (2 or $10 \mathrm{mg} \mathrm{kg}^{-1}$; Figures $1 \mathrm{~A}$ and B). Although CDDP significantly suppressed tumour growth in T24 cells even at the low dose $\left(2 \mathrm{mg} \mathrm{kg}^{-1}\right)$, CDDP did not significantly suppress tumour growth in T24PR cells even at high dose $\left(10 \mathrm{mg} \mathrm{kg}^{-1}\right)$. The apoptotic index of T24PR tumours on the 28th day $(1.67 \pm 0.21, P<0.05)$ was significantly lower than that of T24 tumours $(10.8 \pm 0.60)$ at the high dose of CDDP (Figure 1C). Similar results were also observed at the low dose.

\section{Enhancement of VEGF production through upregulation of AT1R signalling in platinum-resistant bladder cancer sublines}

We examined the changes in VEGF production induced by Ang II. The cells were exposed to Ang II $\left(10^{-7} \mathrm{M}\right)$ with or without olmesartan $\left(10^{-7} \mathrm{M}\right)$, and VEGF in the supernatant was assessed by ELISA (Figure 2A). Ang II induced a further increase of VEGF production in platinum-resistant cell lines compared with those of parent cells, whereas olmesartan significantly inhibited Ang II-induced VEGF production.

Table I Comparison of drug resistance to anticancer agents in 5637, 5637PR, T24, and T24PR cells

\begin{tabular}{|c|c|c|c|c|c|c|c|c|}
\hline \multirow[b]{2}{*}{ Cell line } & \multicolumn{2}{|c|}{ Cisplatin } & \multicolumn{2}{|c|}{ Paclitaxel } & \multicolumn{2}{|c|}{ Gemcitabine } & \multicolumn{2}{|c|}{ Carboplatin } \\
\hline & $I^{\prime} C_{50} \pm$ s.e. $(\mu \mathrm{M})$ & $\mathbf{R F}$ & $I C_{50} \pm$ s.e. (nM) & $\mathbf{R F}$ & $I C_{50} \pm$ s.e. (nM) & $\mathbf{R F}$ & $\mathrm{IC}_{50} \pm$ s.e. $(\mu \mathrm{M})$ & $\mathbf{R F}$ \\
\hline $\begin{array}{l}\text { T24 } \\
\text { T24PR }\end{array}$ & $\begin{array}{r}3.8 \pm 0.3 \\
20.2 \pm 1.2\end{array}$ & 5.3 & $\begin{array}{l}44 \pm 1.0 \\
73 \pm 2.4\end{array}$ & 1.7 & $\begin{array}{l}165 \pm 10 \\
701 \pm 52\end{array}$ & 4.2 & $\begin{aligned} 65 & \pm 4.5 \\
211 & \pm 11\end{aligned}$ & 3.2 \\
\hline
\end{tabular}

Abbreviation: $\mathrm{RF}=$ resistance factor. $I \mathrm{C}_{50}$ values were determined in three independent experiments. $R F=I C_{50}$ of resistant line/IC 50 of parent line.
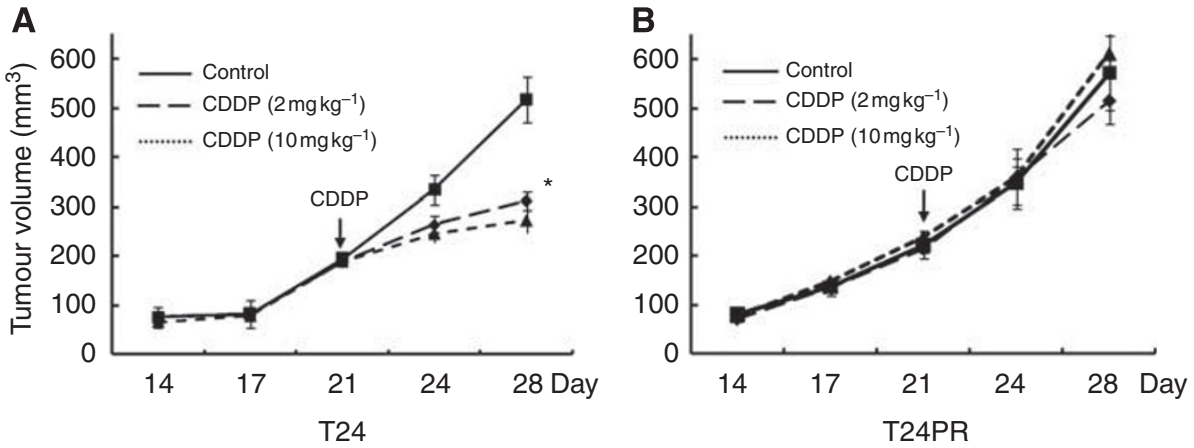

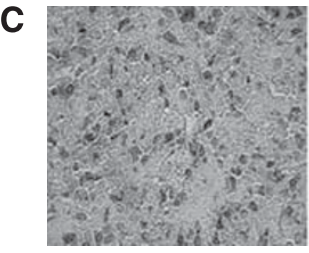

T24

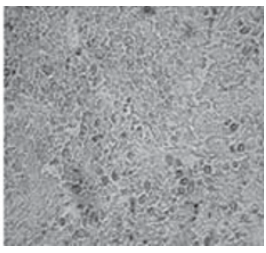

T24PR

Figure I Changes in cell viability and apoptosis induced by CDDP before and after the development of acquired platinum resistance in vivo. For in vivo study, CDDP (2 or $10 \mathrm{mg} \mathrm{kg}^{-1}$ ) was injected intraperitoneally on the 2 Ist day. ${ }^{*} P<0.05$, compared with control group. Each value represents the mean \pm s.e. (A) Time course changes in tumour growth in T24 bladder cancer xenograft models treated with CDDP. (B) Time course changes in tumour growth in T24PR bladder cancer xenograft models treated with CDDP. (C) Serial photo panels showing TUNEL staining of T24 and T24PR mouse xenograft tumours treated with CDDP $\left(10 \mathrm{mg} \mathrm{kg}^{-1}\right)$ on the 28th day. Magnification is I:400. 
A

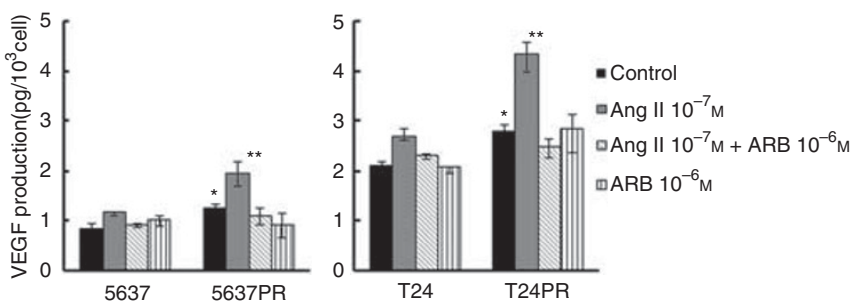

B

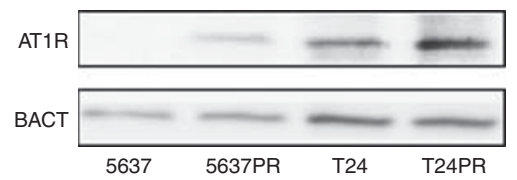

C

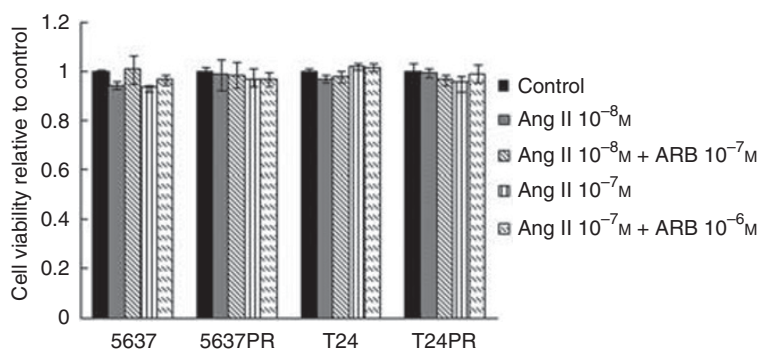

Figure 2 Changes in VEGF production induced by Ang II and ATIR expression before and after the development of acquired platinum resistance. Each value represents the mean \pm s.e. of at least three individual experiments. (A) VEGF measurements in four bladder cancer cell lines after 20-h incubation with and/or without Ang II and olmesartan. $* P<0.05$, compared with corresponding parent cells without Ang II stimulation. *** $P<0.05$, compared with corresponding parent cells with Ang II stimulation. (B) ATIR expression in four bladder cancer cell lines. (C) Effect of Ang II and olmesartan on four bladder cancer cell lines for $48 \mathrm{~h}$.

Next, we examined AT1R expression in each cell line (Figure 2B). Using Western blot analysis, both 5637PR and T24PR showed significantly higher AT1R expression than their corresponding parent cells. To examine the Ang II-inducing effects on cell growth, 5637PR and T24PR cells were incubated with and without Ang II and olmesartan for $48 \mathrm{~h}$ (Figure 2C). In vitro proliferation assay at clinically achievable concentrations of Ang II $\left(10^{-8}\right.$ to $\left.10^{-7} \mathrm{M}\right)$ and olmesartan $\left(10^{-7}\right.$ to $\left.10^{-6} \mathrm{M}\right)$ showed no effects on cell proliferation. Similar results were observed at 24 and $72 \mathrm{~h}$.

\section{Upregulation of ROS generation in platinum-resistant bladder cancer sublines and the free radical scavenger edaravone downregulates the expression of AT1R}

To elucidate the mechanism for upregulating AT1R expression, we investigated ROS generation by measuring DCF production. ROS generation in the platinum-resistant sublines was significantly higher than that of their respective parent cells (Figure 3A). Next, to examine whether increased ROS generation after development of the acquired platinum resistance could affect AT1R expression, we used the free radical scavenger edaravone. To evaluate the edaravone-induced effects on cell growth, T24PR cells were incubated with various concentrations of edaravone. Edaravone showed no effects on cell proliferation for $24 \mathrm{~h}$.

Next, AT1R expression in T24PR cells was evaluated after treating with edaravone, and AT1R expression was significantly downregulated in a time- and dose-dependent manner (Figure 3B). We then evaluated AT1R expression after treating with edaravone in vivo. The results of immunostaining indicated that AT1R expression was significantly suppressed in edaravone-treated
A

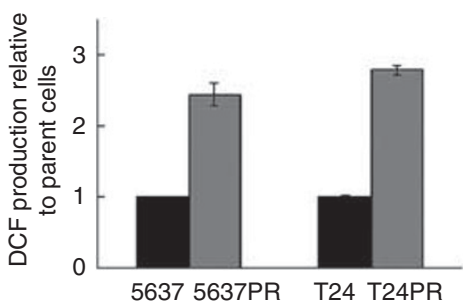

B

\begin{tabular}{|c|c|c|c|c|c|c|}
\hline & \\
\hline \multirow{2}{*}{\multicolumn{3}{|c|}{$\begin{array}{c}\text { Time response } \\
\text { Edaravone } 100 \mu \mathrm{M}\end{array}$}} & & \multirow{2}{*}{\multicolumn{3}{|c|}{$\begin{array}{c}\text { Dose response } \\
\text { Edaravone }(\mu \mathrm{m}) 24 \mathrm{~h}\end{array}$}} \\
\hline & & & & & & \\
\hline Control & $12 \mathrm{~h}$ & $24 \mathrm{~h}$ & \multirow{3}{*}{$\begin{array}{l}\text { AT1R } \\
\text { BACT }\end{array}$} & Control & $10 \mu \mathrm{M}$ & $100 \mu \mathrm{M}$ \\
\hline 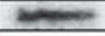 & $=$ & $=$ & & 80 & 20 & 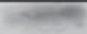 \\
\hline & - & 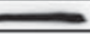 & & - & & \\
\hline
\end{tabular}

Figure 3 Changes in ROS generation before and after the development of acquired platinum resistance, and the regulation of ATIR expression induced by the free radical scavenger edaravone in acquired platinumresistant cells. Each value represents the mean \pm s.e. of at least three individual experiments. (A) ROS generation in four bladder cancer cells was measured by DCF production. (B) Western blotting showed ATIR expression was downregulated, using edaravone in a time- and dosedependent manner.

tumours $(2.5 \pm 0.2$ in the control group $v s \quad 1.1 \pm 0.2$ in the edaravone group, $P<0.05)$, and these results were consistent with those in the in vitro study.

\section{Efficacy of ARB administration in a murine xenograft model of platinum-resistant bladder cancer}

We examined the efficacy of ARB in T24PR tumours. As shown in Figure $4 \mathrm{~A}$, olmesartan $\left(10 \mathrm{mg} \mathrm{kg}^{-1}\right)$ administered daily by gavage significantly suppressed the growth of T24 tumours, and tumour volume was $63.0 \%$ compared with the control group on the 28 th day. Moreover, olmesartan $\left(10 \mathrm{mg} \mathrm{kg}^{-1}\right)$ also significantly suppressed the growth of T24PR tumours (Figure 4B). The tumour volume was decreased to $51.9 \%$ compared with the control group on the 28th day. Significant differences in tumour volume were observed between the ARB-treated group and control group as early as day 24 after tumour implantation.

\section{Changes in MVD, VEGF, and AT1R expression after $A R B$ administration in murine xenograft model of platinum-resistant bladder cancer}

We examined angiogenic parameters using immunohistochemical techniques on the 28th day (Figures $4 \mathrm{C}$ and D). The MVD of T24PR tumours $(7.8 \pm 0.8, P<0.05)$ was significantly higher than that of T24 (4.3 \pm 0.6$)$. T24PR tumours showed significantly higher VEGF expression $(2.5 \pm 0.3, P<0.05)$ than T24 tumours $(1.5 \pm 0.2)$, whereas T24PR tumours also showed significantly higher AT1R expression $(2.5 \pm 0.2, P<0.05)$ than T24 tumours $(1.5 \pm 0.3)$. These results suggest that neovascularisation is the more aggressively induced platinum-resistant tumours, and were consistent with those of AT1R expression.

We then investigated MVD, VEGF, and AT1R expression after ARB treatment. VEGF expression in T24PR tumours was significantly suppressed by olmesartan $(1.3 \pm 0.1, P<0.05)$, whereas the MVD of T24PR tumours was also decreased in the olmesartan group $(3.5 \pm 0.2, P<0.05)$. In addition, olmesartan administration affected the level of AT1R expression $(2.0 \pm 0.1, P<0.05)$. Similarly, the expressions of MVD, VEGF, and AT1R in T24 tumours were also significantly decreased in the olmesartan-treated group. 
A

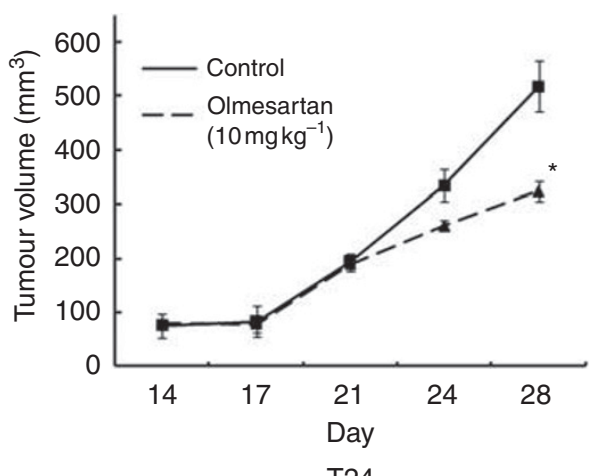

C

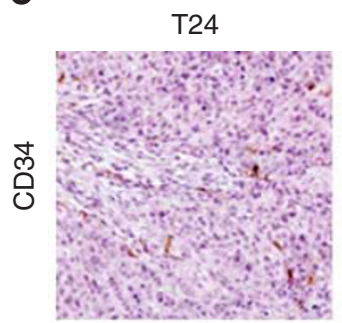

D

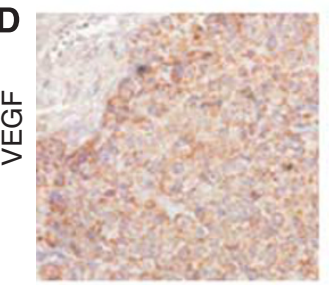

E

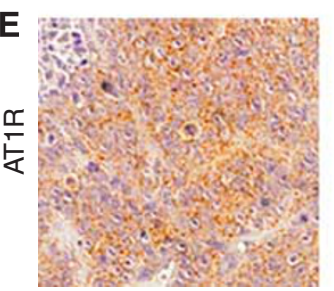

T24

+ Olmesartan
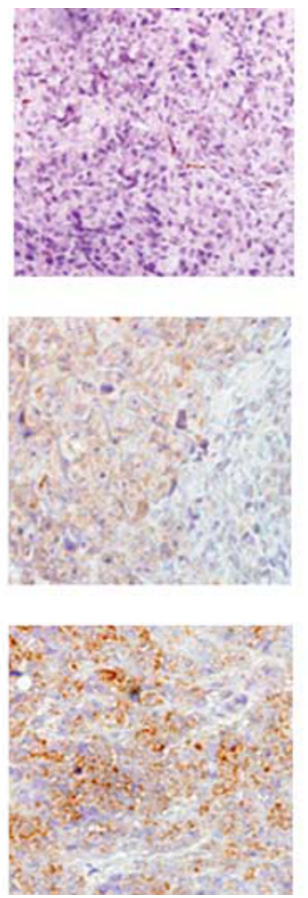

B

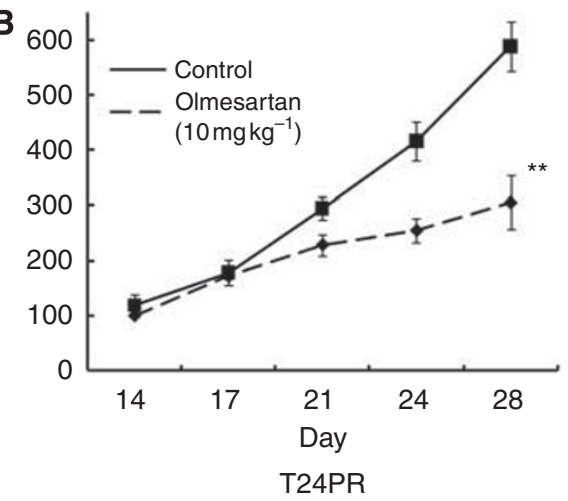

T24PR

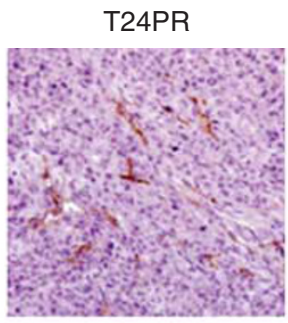

+ Olmesartan
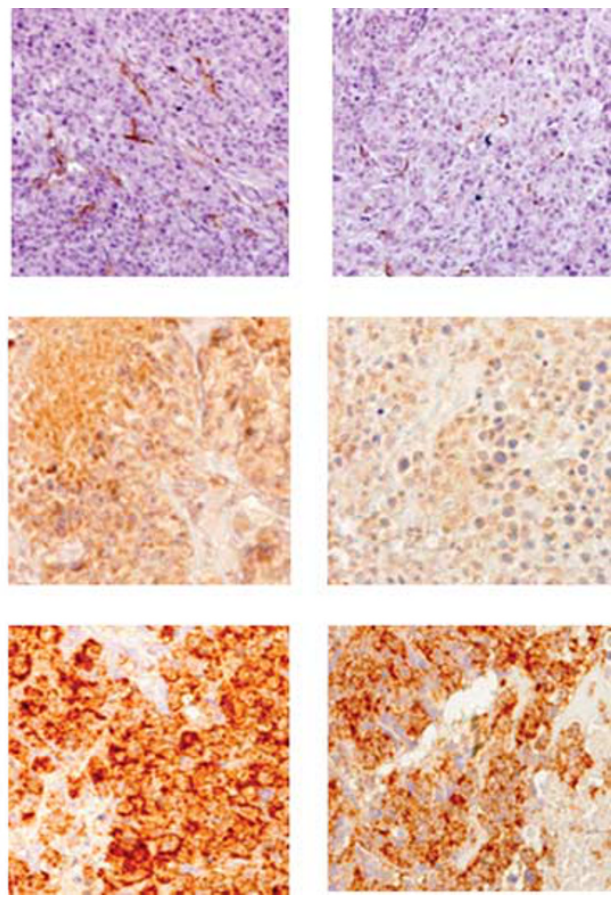

Figure 4 Time course changes in tumour growth in T24 bladder cancer xenograft models $(\mathbf{A})$, and that of T24PR bladder cancer xenograft models treated with olmesartan $(\mathbf{B})$. Olmesartan $\left(10 \mathrm{mg} \mathrm{kg}{ }^{-1}\right.$ per day) was started on the $\mid 4$ th day. $* P<0.05$, compared with control of T24 tumours. $* * P<0.05$, compared with control of T24PR tumours. Serial photo panels showing immunohistochemical staining of CD34 (C), VEGF (D), or ATIR expression (E), in T24 and T24PR tumours with or without olmesartan on the 28th day. Magnification is I:400.

Therefore, AT1R blockade might be effective even after the tumours developed acquired platinum resistance.

\section{Effect of combination therapy with paclitaxel and ARB in murine xenograft model of platinum-resistant bladder cancer}

Although results in a WST-1 assay indicated the sensitivity of paclitaxel did not change dramatically, compared with other agents, we evaluated the efficacy of paclitaxel monotherapy in T24PR tumours. As shown in Figure $5 \mathrm{~A}$, paclitaxel (5 or $15 \mathrm{mg} \mathrm{kg}^{-1}$ ) was administered on day 21 after cancer cell implantation, and tumour growth was significantly suppressed in a dose-dependent manner. We then investigated the efficacy of the combination of paclitaxel and ARB. As shown in Figure 5B, olmesartan $\left(10 \mathrm{mg} \mathrm{kg}^{-1}\right)$ was administered daily by gavage from day 14 after cancer cell implantation, and the tumour growth was significantly suppressed in paclitaxel + ARB-treated tumours, compared with paclitaxel only $(P<0.05)$.

\section{DISCUSSION}

In the present study, we analysed two different molecular events that occurred after the development of acquired platinum resistance in bladder cancer. First, ROS generation induced by cancer cells was significantly increased after the development of acquired platinum resistance, and second, AT1R expression in these cells was significantly upregulated through increased ROS generation, resulting in more angiogenic aggressiveness. On the basis of these molecular mechanisms, we also showed the efficacy of AT1R blockade against platinum-resistant tumours. To the best of our knowledge, this is the first report that shows a correlation between increased ROS generation and AT1R expression after the development of acquired platinum resistance, and the significance of AT1R blockade as a new modality for platinum-resistant bladder cancer.

The prognosis for patients with advanced or metastatic bladder cancer remains poor. The vast majority of patients treated with CDDP-based regimens develop progressive disease within 8 

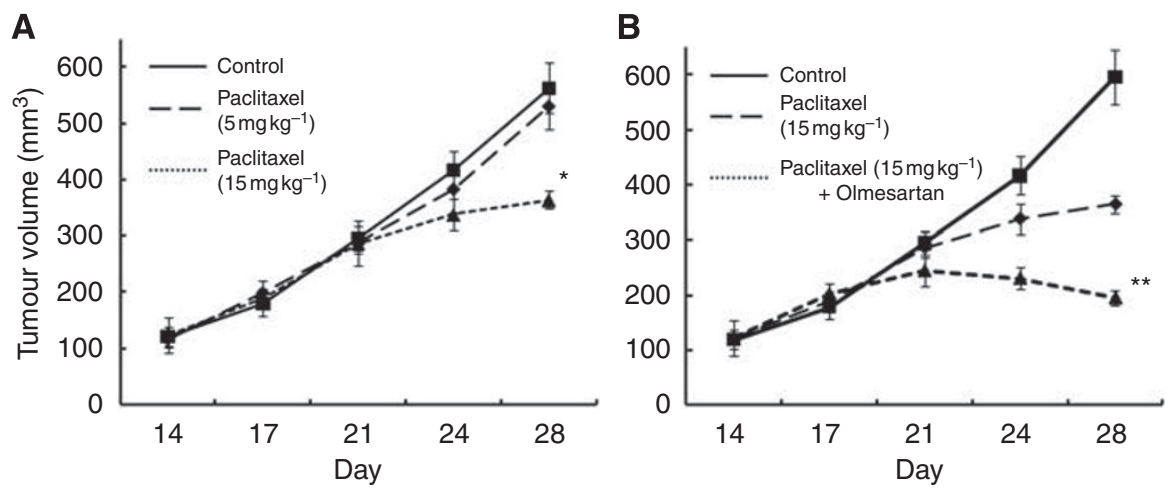

Figure 5 Time course changes in tumour growth in T24PR bladder cancer xenograft models treated with paclitaxel only $(\mathbf{A})$. Paclitaxel $\left(5\right.$ or I 5 mg $\left.\mathrm{kg}^{-1}\right)$ was injected intraperitoneally on the 21 st day. ${ }^{*} P<0.05$, compared with control group. Time course changes in tumour growth in T24PR bladder cancer xenograft models treated with paclitaxel and olmesartan (B). Olmesartan ( $10 \mathrm{mg} \mathrm{kg}^{-1}$ per day) was started on the 14 th day, and paclitaxel $\left(15 \mathrm{mg} \mathrm{kg}{ }^{-1}\right)$ was injected intraperitoneally on the 2 I st day. ${ }^{*} P<0.05$, compared with paclitaxel-only group.

months of treatment, and the median survival is reported to be only 13-15 months (von der Maase et al, 2000). There currently is still no approved treatment option for patients who develop disease recurrence or progression after CDDP-based regimens.

Increased ROS generation in cancer cells correlates with their tumour aggressiveness and poor prognosis, and previous reports have suggested that the increased ROS generation in cancer cells has a pivotal role in the acquisition of the hallmarks of cancer (Patel et al, 2007; Kumar et al, 2008). In contrast, if the increase of ROS generation reaches a certain threshold level that is incompatible with cellular survival, ROS generation may exert a cytotoxic effect, leading to the death of cancer cells and thus limiting tumour progression $(\mathrm{Wu}, 2006$; Fruehauf and Meyskens, 2007). Taken together, ROS generation may work as a doubleedged sword, and this paradoxical effect is particularly interesting in terms of how cancer cells can gain growth and survival benefits under intrinsic oxidative stress.

To investigate the association between ROS generation and AT1R expression after the development of acquired platinum resistance, we selected two different cell lines: 5637, which is comparatively resistant to CDDP and has a low level of AT1R, and T24, which is sensitive to CDDP and has a high level of AT1R. We examined the changes in VEGF production induced by Ang II and AT1R expression. In vitro study showed that Ang II induced further increases in VEGF production in both the platinumresistant cells, compared with those of their parent cells. Similarly, both platinum-resistant cells exhibited significantly higher levels of AT1R expression than their parent cells. These results suggest that long-term exposure to CDDP might affect AT1R expression even if the tumours do not show a high level of AT1R expression before CDDP-treatment.

We then examined the changes in ROS generation. ROS generation induced by cancer cells was significantly upregulated in 5637PR and T24PR cells compared with their corresponding parent cells, and were correlated with the changes of AT1R expression. Moreover, we also showed that suppressing ROS generation could significantly induce the downregulation of AT1R expression in acquired platinum-resistant cancer cells. These results suggest a possible molecular mechanism for tumour aggressiveness after the development of acquired platinum resistance that may originate in upregulating the AT1R expression induced by increased ROS generation.

New agents with improved efficacy and adequate tolerability would be needed for patients with advanced bladder cancer who have previously received a CDDP-based regimen. Treatment for these patients is further complicated by poor performance status, comorbidities, and inadequate renal function.

Although angiogenesis in cancer cells is regulated by many mechanisms, it may be controversial as to whether the AT1R pathway is a major regulator of VEGF production, or whether other mechanisms exist. The present study did not fully elucidate whether upregulated AT1R expression could affect the sensitivity to ARBs. However, our results strongly suggest that ARB olmesartan could suppress tumour growth even in the acquired platinum-resistant tumours.

Previous studies also reported the efficacy of AT1R blockade in cancer treatments. Wilop et al (2009) analysed retrospectively 287 patients with advanced non-small cell lung cancer undergoing first-line platinum-based chemotherapy, and reported that patients who received angiotensin-converting enzyme inhibitors or ARBs had a longer survival than non-recipients. Nakai et al (2010) reported that the use of angiotensin-converting enzyme inhibitors or ARBs with gemcitabine was an independent prognostic factor for both progression-free survival and overall survival in patients with advanced pancreatic cancer. Two prospective studies also proposed the potency of AT1R blockade in cancer treatment (Yoshiji et al, 2009; Tatokoro et al, 2011). Although an increasing body of evidence suggests the efficacy of ARBs may be promising, we examined the effect of combination therapy consisting of CDDP and olmesartan in T24PR tumours, and found no significant difference in tumour growth between the ARB-only group and CDDP + ARB-treated group (data not shown). Therefore, administration of an ARB may not change the sensitivity to CDDP once a tumour has developed acquired platinum resistance. On the other hand, as shown in Figure 5, although the sensitivity to paclitaxel did not change dramatically compared with other agents, the use of combination therapy with taxane agents (paclitaxel or docetaxel) and ARBs may yield promising results in patients with acquired platinumresistant tumours.

In summary, acquired platinum resistance may induce more angiogenic aggressiveness through upregulating AT1R expression induced by increased ROS generation in bladder cancer. These findings suggest a new molecular mechanism for AT1R signalling when tumours progress after CDDP-based regimens. As ARBs, which are antihypertensive agents, are already in clinical use without severe side effects, from a clinical point of view, we propose they may be an effective choice in patients who develop disease recurrence or progression after CDDP-treatment.

\section{ACKNOWLEDGEMENTS}

This study was supported in part by Grants-in-Aid for Scientific Research (No. 22791495 to Tanaka N, No. 22591777 to Miyajima A, and No. 21390455 to Oya M) from the Ministry of Education, Culture, Sports, Science, and Technology of Japan. 


\section{REFERENCES}

Egami K, Murohara T, Shimada T, Sasaki K, Shintani S, Sugaya T, Ishii M, Akagi T, Ikeda H, Matsuishi T, Imaizumi T (2003) Role of host angiotensin II type 1 receptor in tumor angiogenesis and growth. J Clin Invest 112: $67-75$

Fruehauf JP, Meyskens Jr FL (2007) Reactive oxygen species: a breath of life or death? Clin Cancer Res 13: 789-794

Juillerat-Jeanneret L, Celerier J, Chapuis Bernasconi C, Nguyen G, Wostl W, Maerki HP, Janzer RC, Corvol P, Gasc JM (2004) Renin and angiotensinogen expression and functions in growth and apoptosis of human glioblastoma. $\mathrm{Br} J$ Cancer 90: $1059-1068$

Kosaka T, Miyajima A, Shirotake S, Kikuchi E, Hasegawa M, Mikami S, Oya M (2010) Est-1 and hypoxia inducible factor-1 $\alpha$ inhibition by angiotensin II type 1 receptor blockade in hormone-refractory prostate cancer. Prostate 70: $162-169$

Kosaka T, Miyajima A, Takayama E, Kikuchi E, Nakashima J, Ohigashi T, Asano T, Sakamoto M, Okita H, Murai M, Hayakawa M (2007) Angiotensin II type 1 receptor antagonist as an angiogenic inhibitor in prostate cancer. Prostate 67: $41-49$

Kosugi M, Miyajima A, Kikuchi E, Horiguchi Y, Murai M (2006) Angiotensin II type 1 receptor antagonist candesartan as an angiogenic inhibitor in a xenograft model of bladder cancer. Clin Cancer Res 12: 2888-2893

Kosugi M, Miyajima A, Kikuchi E, Kosaka T, Horiguchi Y, Murai M, Oya M (2009) Angiotensin II type 1 receptor antagonist enhances cis-dichlorodiammineplatinum-induced cytotoxicity in mouse xenograft model of bladder cancer. Urology 73: 655-660

Kumar B, Koul S, Khandrika L, Meacham RB, Koul HK (2008) Oxidative stress is inherent in prostate cancer cells and is required for aggressive phenotype. Cancer Res 68: $1777-1785$

Lau ST, Lin ZX, Leung PS (2010) Role of reactive oxygen species in brucein D-mediated p38-mitogen-activated protein kinase and nuclear factorkappaB signalling pathways in human pancreatic adenocarcinoma cells. Br J Cancer 102: $583-593$

Lee JM (1998) Inhibition of p53-dependent apoptosis by the KIT tyrosine kinase: regulation of mitochondrial permeability transition and reactive oxygen species generation. Oncogene 17: 1653-1662

Miyajima A, Kosaka T, Asano T, Asano T, Seta K, Kawai T, Hayakawa M (2002) Angiotensin II type 1 antagonist prevents pulmonary metastasis of murine renal cancer by inhibiting tumor angiogenesis. Cancer Res 62: 4176-4179

Nakai Y, Isayama H, Ijichi H, Sasaki T, Sasahira N, Hirano K, Kogure H, Kawakubo K, Yagioka H, Yashima Y, Mizuno S, Yamamoto K, Arizumi T, Togawa O, Matsubara S, Tsujino T, Tateishi K, Tada M, Omata M, Koike K (2010) Inhibition of renin-angiotensin system affects prognosis of advanced pancreatic cancer receiving gemcitabine. $\mathrm{Br} J$ Cancer 103: $1644-1648$

Patel BP, Rawal UM, Dave TK, Rawal RM, Shukla SN, Shah PM, Patel PS (2007) Lipid peroxidation, total antioxidant status, and total thiol levels predict overall survival in patients with oral squamous cell carcinoma. Integr Cancer Ther 6: $365-372$

Puri PL, Avantaggiati ML, Burgio VL, Chirillo P, Collepardo D, Natoli G, Balsano C, Levrero M (1995) Reactive oxygen intermediates mediate angiotensin II-induced c-Jun.c-Fos heterodimer DNA binding activity and proliferative hypertrophic responses in myogenic cells. J Biol Chem 270: $22129-22134$

Rivera E, Arrieta O, Guevara P, Duarte-Rojo A, Sotelo J (2001) AT1 receptor is present in glioma cells; its blockage reduces the growth of rat glioma. Br J Cancer 85: $1396-1399$

Schreck R, Meier B, Männel DN, Dröge W, Baeuerle PA (1992) Dithiocarbamates as potent inhibitors of nuclear factor $\kappa \mathrm{B}$ activation in intact cells. J Exp Med 175: $1181-1194$

Stevenson MA, Pollock SS, Coleman CN, Calderwood SK (1994) X-irradiation, phorbol esters, and $\mathrm{H}_{2} \mathrm{O}_{2}$ stimulate mitogen-activated protein kinase activity in $\mathrm{NIH}-3 \mathrm{~T} 3$ cells through the formation of reactive oxygen intermediates. Cancer Res 54: $12-15$

Tanaka N, Miyajima A, Kosaka T, Shirotake S, Hasegawa M, Kikuchi E, Oya M (2010) Cis-dichlorodiammineplatinum upregulates angiotensin II type 1 receptors through reactive oxygen species generation and enhances VEGF production in bladder cancer. Mol Cancer Ther 9: $2982-2992$

Tatokoro M, Fujii Y, Kawakami S, Saito K, Koga F, Matsuoka Y, Iimura Y, Masuda H, Kihara K (2011) Phase-II trial of combination treatment of interferon- $\alpha$, cimetidine, cyclooxygenase- 2 inhibitor and renin-angiotensin-system inhibitor (I-CCA therapy) for advanced renal cell carcinoma. Cancer Sci 102: $137-143$

von der Maase H, Hansen SW, Roberts JT, Dogliotti L, Oliver T, Moore MJ, Bodrogi I, Albers P, Knuth A, Lippert CM, Kerbrat P, Sanchez Rovira P, Wersall P, Cleall SP, Roychowdhury DF, Tomlin I, Visseren-Grul CM, Conte PF (2000) Gemcitabine and cisplatin versus methotrexate, vinblastine, doxorubicin, and cisplatin in advanced or metastatic bladder cancer: results of a large, randomized, multinational, multicenter, phase III study. J Clin Oncol 18: $3068-3077$

Wilop S, von Hobe S, Crysandt M, Esser A, Osieka R, Jost E (2009) Impact of angiotensin I converting enzyme inhibitors and angiotensin II type 1 receptor blockers on survival in patients with advanced non-small-cell lung cancer undergoing first-line platinum-based chemotherapy. J Cancer Res Clin Oncol 135: 1429-1435

Wu WS (2006) The signaling mechanism of ROS in tumor progression. Cancer Metastasis Rev 25: 695-705

Yoshiji H, Noguchi R, Toyohara M, Ikenaka Y, Kitade M, Kaji K, Yamazaki M, Yamao J, Mitoro A, Sawai M, Yoshida M, Fujimoto M, Tsujimoto T, Kawaratani H, Uemura M, Fukui H (2009) Combination of vitamin K2 and angiotensin-converting enzyme inhibitor ameliorates cumulative recurrence of hepatocellular carcinoma. J Hepatol 51: 315-321

This work is published under the standard license to publish agreement. After 12 months the work will become freely available and the license terms will switch to a Creative Commons Attribution-NonCommercial-Share Alike 3.0 Unported License. 